\title{
Workshop Guru SDN Melayu 7 Banjarmasin dalam Menyusun Soal Cerita Berbasis Kearifan Lokal untuk Meningkatkan Kemampuan Berpikir Kreatif
}

\author{
Workshop for SDN Melayu 7 Banjarmasin Teachers in Developing Local Wisdom-Based Story \\ Questions to Improve Creative Thinking Ability
}

Aminah Ekawati*
Winda Agustina
Hajjah Rafiah
Department of Mathematics
Education, Sekolah Tinggi
Keguruan dan Ilmu Pendidikan
PGRI Banjarmasin, Banjarmasin,
South Kalimantan, Indonesia
"email:
aminahekawati@stkipbjm.ac.id
Kata Kunci
Berpikir Kreatif
Kearifan Lokal
Soal Cerita
Keywords:
Creative thinking
Local culture
Problem Story
Received: September 2019
Pccepted: November 2019

\begin{abstract}
Abstrak
SDN Melayu 7 terletak di Banjarmasin Tengah dan sudah menerapkan kurikulum 2013. Terdapat beberapa permasalahan yang ditemukan dari hasil wawancara dengan kepala sekolah dan beberapa guru, yaitu siswa lebih banyak dihadapkan pada soal-soal rutin dan dituntut untuk mampu menyelesaikan masalah-masalah pada soal cerita. Sedangkan guru kesulitan membuat soal cerita yang mudah dipahami siswa. Kegiatan pengabdian pada masyarakat ini bertujuan agar guru mengetahui bagaimana menyusun soal cerita berbasis kearifan lokal Kalimantan Selatan untuk meningkatkan kemampuan berpikir kreatif. Pendekatan yang digunakan dalam pengabdian ini adalah participant active learning. Kegiatan dibagi menjadi 2 tahap, tahap I difokuskan pada soal cerita berbasis kearifan local Kalimantan selatan sedangkan pada tahap II difokuskan pada soal cerita berbasis kearifan local yang dapat meningkatkan kemampuan berpikir kreatif. Untuk mengukur keberhasilan setiap tahapan diberikan angket pemahaman dan dilihat hasil kerja kelompok peserta. Kegiatan dikatakan berhasil jika rerata angket pemahaman minimal $75 \%$. Hasil kegiatan menunjukkan tingkat pemahaman peserta mencapai $93,61 \%$ pada tahap I dan $91,94 \%$ pada tahap II. Selain itu dilihat dari hasil kerja kelompok dapat disimpulkan bahwa peserta dapat memahami dengan baik penjelasan yang diberikan oleh narasumber.
\end{abstract}

\begin{abstract}
SDN Melayu 7 is located in Banjarmasin Tengah and has implemented the 2013 curriculum. There are some problems found from interviews with the principal and some teachers, namely students, are more faced with routine questions and are required to be able to solve problems in the story of the question. While the teacher has difficulty making story questions that are easily understood by students. This activity aims to prepare teachers to know how to arrange story problems based on local wisdom in South Kalimantan to improve creative thinking skills. The approach used is active participant learning. The activity is divided into two stages, and stage I is focused on the question of story problems based on local wisdom in South Kalimantan, while in stage II, it is focused on the question of story problems based on local wisdom that can improve the ability to think creatively. To measure the success of each stage, an understanding questionnaire was given, and the work of the participant groups were seen. The activity is said to be successful if the average questionnaire comprehension is at least $75 \%$. The results of the activity showed the level of understanding of the participants reached $93.61 \%$ in stage I and $91.94 \%$ in stage II. Also seen from the results of group work it can be concluded that participants can understand well the explanations given by the speakers.
\end{abstract}




\section{PENDAHULUAN}

Pendidikan dasar merupakan dasar bagi jenjang pendidikan menengah. Salah satu tujuan satuan pendidikan dasar yang sejalan dengan Peraturan Pemerintah Nomor 17 Tahun 2010 Tentang Pengelolaan dan Penyelenggaraan Pendidikan, yaitu membangun landasan bagi berkembangannya potensi siswa agar menjadi manusia yang berilmu, cakap, kritis, kreatif, dan inovatif. Demi tercapainya tujuan tersebut, seluruh masyarakat perlu saling bahu-membahu meningkatkan kualitas pendidikan.

Berdasarkan visi dan misi pembangunan jangka menengah Provinsi Kalimantan Selatan tahun 2016-2021, maka ditetapkan tujuan dan sasaran, serta prioritas pembangunan. Misi ketiga pembangunan jangka menengah Provinsi Kalimantan Selatan, yaitu memantapkan kondisi sosial budaya daerah yang berbasiskan kearifan lokal. Salah satu tujuan misi ini adalah meningkatkan kualitas kehidupan yang berbasiskan kearifan lokal. Budaya dipandang sebagai kepercayaan, adat istiadat, norma-norma artistik, kebiasaan makan, keahlian yang diperoleh bukan dari kreativitasnya sendiri melainkan merupakan warisan masa lampau yang didapat melalui pendidikan formal atau informal (Pemerintah Provinsi Kalimantan Selatan, 2016).

Saat ini hampir semua sekolah sudah menerapkan kurikulum 2013. Pada jenjang SD/MI, mata pelajaran terbagi menjadi dua kelompok yaitu kelompok A yang kontennya dikembangkan oleh pusat dan kelompok B yang kontennya tidak hanya dikembangkan oleh pusat tetapi juga dilengkapi dengan konten lokal yang dikembangkan oleh pemerintah daerah. Sesuai dengan penjelasan pada kurikulum 2013, proses pembelajaran yang dikembangkan menghendaki kesabaran guru dalam mendidik siswa sehingga mereka menjadi tahu, mampu dan mau belajar dan menerapkan apa yang sudah mereka pelajari di lingkungan sekolah dan masyarakat sekitarnya (Rasyid, 2008). Hal ini mengindikasikan bahwa hendaknya pendidikan dasar dapat menjadikan siswa mampu menerapkan pengetahuannya dalam kehidupan sehari-hari.

Indonesia secara rutin masuk dalam studi internasional untuk mengukur kemampuan siswa di bidang matematika dan sains seperti TIMSS (Trend in International Mathematics and Science Study). Pada tahun 2015, target populasinya adalah kelas 4 SD/MI. Pencapaian skor sains siswa Indonesia berada pada ranking 45 dan 48 negara, sedangkan skor matematika berada pada ranking 45 dan 50 negara. Hasil analisis menunjukkan, siswa Indonesia menguasai soal-soal atau masalah yang bersifat rutin, komputasi sederhana, serta mengukur pengetahuan akan fakta yang berkonteks keseharian. Siswa Indonesia masih perlu penguatan kemampuan mengintegrasikan informasi, menarik kesimpulan, serta menggeneralisir pengetahuan yang dimiliki ke hal-hal yang lain (McComas, 2014). Kenyataan ini menunjukkan bahwa kemampuan matematika dan sains siswa masih jauh tertinggal dari negara-negara lainnya.

Salah satu tugas penting dari seorang guru adalah membantu siswa-siswanya agar mampu mengembangkan kemampuannya (Manizar, 2015). Tugas ini memang tidak mudah, membutuhkan waktu dan latihan yang cukup panjang. Siswa harus memperoleh sebanyak mungkin pengalaman kerja mandiri agar terbiasa menggeneralisir pengetahuannya. Generalitas merupakan karakteristik penting dari memecahkan suatu masalah. Siswa dapat membuat beberapa pertanyaan terkait masalah. Pertanyaanpertanyaan yang masuk akal tersebut mungkin dapat membantu siswa memecahkan masalah (Polya, 1973). Hal ini menjadi penting, karena soal yang berbasis masalah dalam soal cerita selalu ada pada soal ulangan 
harian, ulangan kenaikan kelas, maupun ujian nasional pada semua jenjang pendidikan.

Pada pembelajaran, masalah kontekstual dapat dituangkan dalam bentuk soal cerita. Soal cerita merupakan cerita atau masalah sederhana yang mengacu pada pengalaman kontekstual. Pembelajaran dengan pengajuan masalah (soal cerita) dapat meningkatkan kemampuan berpikir kreatif siswa pada aspek pemahaman terhadap informasi masalah, kebaruan, dan kefasihan dalam menjawab soal (Siswono, 2005; Rafiah \& Ekawati, 2017; Noor \& Agustina, 2016). Selanjutnya, tingkat berpikir kreatif dapat ditentukan berdasarkan indikator seperti disajikan pada Gambar 1 berikut (Agustina \& Noor, 2016).

\begin{tabular}{cccc}
\hline Tingkat & \multicolumn{3}{c}{ Indikator } \\
\cline { 2 - 4 } $\begin{array}{c}\text { Berpikir } \\
\text { Kreatif }\end{array}$ & Kefasihan & Fleksibel & Kebaruan \\
\hline 4 & $\sqrt{n}$ & $\sqrt{ }$ & $\sqrt{ }$ \\
(sangat & - & $\sqrt{ }$ & \\
kreatif) & & & $\sqrt{ }$ \\
3 & $\sqrt{ }$ & - & - \\
(kreatif) & $\sqrt{ }$ & $\sqrt{ }$ & - \\
2 & - & $\sqrt{ }$ & - \\
(cukup & - & - & - \\
kreatif) & & & \\
1 & $\sqrt{ }$ & - & - \\
(kurang & & & \\
kreatif) & & & \\
0 & - & - & \\
(tidak kreatif) & & & \\
\hline
\end{tabular}

Gambar 1. Pelatihan Kader Lansia

SDN Melayu 7 terletak di kecamatan Banjarmasin Tengah, kota Banjarmasin, berjarak 4,2 km dari kampus STKIP PGRI Banjarmasin. Sekolah berada di daerah pengembangan dan termasuk wilayah pinggiran. Sekolah ini terdiri dari 6 rombongan belajar. Situasi lingkungan cukup kondusif untuk pelaksanaan pembelajaran dan sudah menerapkan kurikulum 2013. Namun, terdapat beberapa permasalahan yang ditemukan dari hasil wawancara dengan kepala sekolah dan beberapa guru, yaitu siswa lebih banyak dihadapkan pada soal-soal rutin dan dituntut untuk mampu menyelesaikan masalah-masalah pada soal cerita. Sedangkan guru kesulitan membuat soal cerita yang mudah dipahami siswa. Untuk mengembangkan kemampuan siswa menyelesaikan soal cerita diperlukan pembiasaan oleh guru. Kesulitan semakin bertambah karena soal cerita yang diberikan tidak sesuai dengan kehidupan siswa sehari-hari (Rahmawati, 2019).

Guru hanya mengandalkan buku paket yang disediakan pemerintah sehingga siswa sulit untuk membayangkan dan menyelesaikan masalah yang diberikan. Guru cenderung enggan membuat soal cerita sendiri karena merasa cukup dengan buku paket yang diberikan pemerintah dan karena soal ulangan disusun oleh KKG (Insani, 2016). Selain itu, guru kesulitan mengaitkan konsep-konsep matematika dengan kearifan lokal karena guru tidak begitu memahami tentang lingkup kearifan lokal Kalimantan Selatan. Guru tidak terbiasa memandang kearifan lokal dari berbagai sisi yang dapat dimanfaatkan sebagai konten pembelajaran matematika. Dari sisi siswa, mereka tidak dapat mengembangkan kemampuan berpikir kreatifnya dengan soal-soal rutin. Oleh karena terbiasa dengan soal rutin, maka siswa kesulitan saat menghadapi soal cerita yang merupakan penerapan dari suatu konsep. Karena siswa terbiasa dengan cara diberikan contoh oleh guru saja, sehingga jarang memberikan jawaban yang bervariasi. Terlebih jika soal cerita tersebut sulit mereka bayangkan (Mulyati, 2011).

Pendidikan Matematika Realistik (PMR) berbasis ethnomathematics dapat mengembangkan kreativitas siswa (Budiarti \& Agustina, 2017). Hasil penelitian ini menunjukkan bahwa kearifan lokal dapat dimasukkan ke dalam konten pembelajaran dengan model pembelajaran yang sesuai agar kreativitas siswa berkembang. Asesmen pemecahan masalah open-ended berupa lembar-lembar pemecahan masalah open-ended 
Setiap lembar pemecahan masalah open-ended berisi satu masalah open-ended beserta lembar jawabannya. Masalah open-ended yang digunakan memiliki dua kriteria yaitu memiliki banyak cara atau strategi penyelesaian dan memiliki banyak jawaban benar (Sa'dijah et al, 2016). Berdasarkan uraian analisis situasi tersebut, maka perlu diupayakan suatu solusi pemecahan masalah yang ada di SDN Melayu 7 Banjarmasin yaitu workshop guru dalam menyusun soal cerita berbasis kearifan local untuk meningkatkan kemampuan berpikir kreatif.

\section{METODOLOGI}

Pengabdian penyusunan soal cerita berbasis kearifan lokal untuk meningkatkan kemampuan berpikir kreatif siswa dilaksanakan di SDN Melayu 7 dengan sasaran jumlah guru yang mengikuti pendampingan ini sebanyak 8 orang termasuk kepala sekolah. Pendekatan yang digunakan dalam pengabdian ini adalah participant active learning, yaitu peserta aktif berpartisipasi pada kegiatan pendampingan pengembangan soal cerita berbasis kearifan lokal untuk meningkatkan kemampuan berpikir kreatif siswa. Metode yang digunakan adalah ceramah, tanya jawab terkait materi pelatihan, diskusi fasilitator dengan peserta, dan mengerjakan lembar kerja. Kegiatan pengabdian dibagi menjadi 2 tahapan yaitu tahapan pendampingan pengembangan soal cerita berbasis kearifan lokal dan tahapan pengembangan soal cerita untuk meningkatkan kemapuan berpikir kreatif. Untuk mengetahui pemahaman peserta terhadap materi yang disampaikan maka diberikan angket pemahaman dengan tiga indikator utama yaitu:

1. Isi materi

2. Pemaparan

3. Diskusi
Indikator keberhasilan pengabdian jika hasil persentase angket pemahaman peserta minimal 75\%.

\section{HASIL DAN PEMBAHASAN}

Kegiatan pengabdian pada masyarakat SDN Melayu 7 Banjarmasin terdiri atas tiga tahap yaitu: 1) tahap perencanaan, 2) tahap pelaksanaan kegiatan, dan 3) tahap evaluasi kegiatan. Tahapan perencanaan dilaksanakan dimulai dengan tim menyusun dan merancang rencana yang akan dilakukan seperti membuat materi, angket, dan membagi tugas dengan melibatkan mahasiswa yang bertindak sebagai petugas lapangan.

Tim melakukan koordinasi dengan kepala sekolah berkaitan dengan jadwal yang akan dilaksanakan untuk kegiatan pengabdian pada tanggal 29 Maret 2019. Kegiatan pengabdian yang dilaksanakan tidak menggangu kegiatan guru dan siswa di sekolah, sehingga sebisa mungkin dilaksanakan pada saat anakanak pulang sekolah. Berikut jadwal kegiatan yang dilaksanakan sebagaimana disajikan pada Tabel I.

Tabel I. Jadwal Kegiatan Pengabdian

\begin{tabular}{llcc}
\hline No & Traian & Tanggal & Pukul \\
\hline 1 Tahap I & 6-Apr-19 & $12.00-14.00$ \\
& (Kearifan lokal Kalimantan Selatan) & 13-Apr-19 & $12.00-14.00$ \\
& 16-Apr-19 $12.00-15.00$ \\
2 Tahap II & 23-Apr-19 $12.00-14.00$ \\
& (Kemampuan berpikir kreatif) & 24-Apr-19 $12.00-14.00$ \\
& 25-Apr-19 $12.00-15.00$ \\
\hline
\end{tabular}

Konten masalah dalam pembelajaran dapat dikaitkan dengan kehidupan sekitar siswa. Contohnya matematika, aktivitas matematika yang biasanya dianggap abstrak oleh siswa menjadi lebih konkrit dengan dikaitkan dengan unsur budaya lokal (Ekowati et al., 2017). Kearifan lokal Kalimantan Selatan yang beragam dapat dimanfaatkan secara maksimal, tidak hanya untuk mempermudah siswa memahami masalah dalam soal cerita, tetapi juga sebagai bagian dari mewujudkan misi pembangunan pemerintah Provinsi 
Kalimantan Selatan, yaitu meningkatkan kualitas kehidupan yang berbasis kearifan lokal.

Kegiatan tahap I terdiri dari tiga kegiatan yaitu pengenalan kearifan lokal Kalimantan Selatan, menganalisis Standar Isi, dan Penyusunan soal cerita yang berbasis kearifan lokal Kalimantan Selatan. Kegiatan tahap II terdiri dari tiga kegiatan yaitu penjelasan tentang kemampuan berpikir kreatif siswa, cara menilai kemampuan berpikir kreatif siswa, dan mengembangkan soal cerita berbasis kearifan lokal Kalimantan Selatan yang dapat meningkatkan kemampuan berpikir kreatif siswa.

Kegiatan tahap I bertujuan agar guru mengetahui bagaimana menyusun soal cerita berbasis kearifan lokal Kalimantan Selatan. Selama kegiatan berlangsung peserta antusias mengikuti kegiatan. Jika ada hal yang tidak dimengerti peserta memberikan pertanyaan kepada narasumber sehingga kegiatan pengabdian terjadi dua arah. Berikut gambaran kegiatan tahap I sebagaimana disajikan pada Gambar 2.

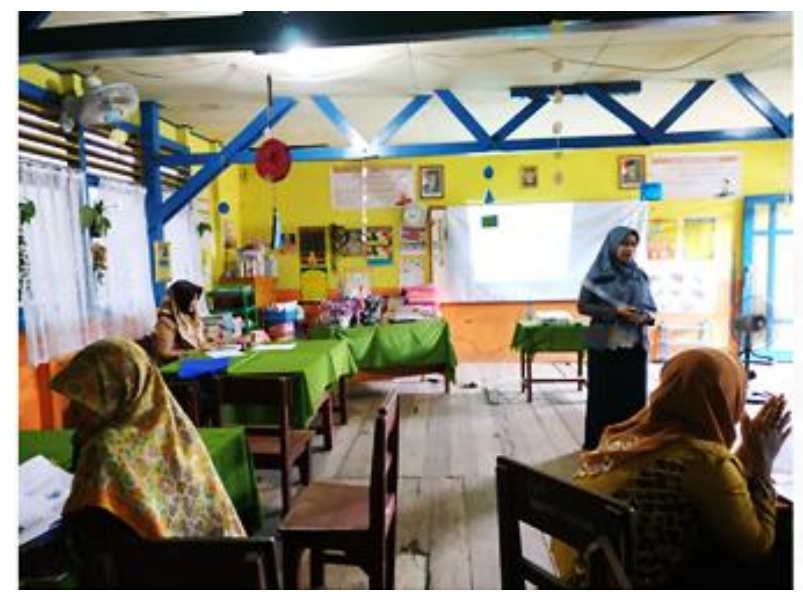

Gambar 2. Peserta mendengarkan narasumber menyampaikan kegiatan tahap I

Pada setiap kegiatan peserta mengerjakan lembar kerja kelompok, dari lembar kerja kelompok ini dapat dilihat pemahaman peserta terhadap materi yang disampaikan oleh narasumber seperti disajikan pada Gambar 3.

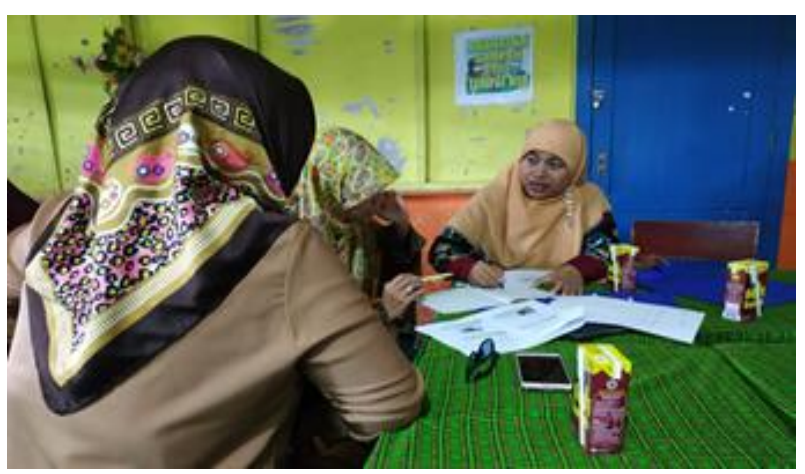

Gambar 3. Peserta berdiskusi mengerjakan lembar kerja pada kegiatan tahap I

Pada Gambar 4 berikut adalah salah satu hasil kerja kelompok yang dibuat oleh peserta.

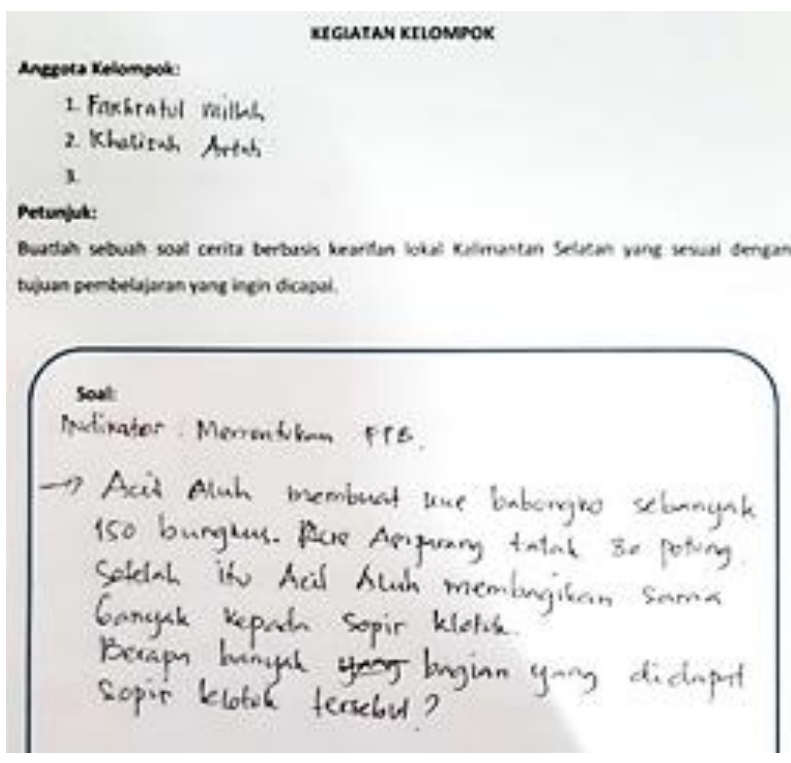

Gambar 4. Hasil kerja kelompok kegiatan tahap I

Pada Gambar 3 terlihat bahwa peserta mencoba membuat soal cerita dengan menggunakan konten kearifan local yaitu mengangkat kue tradisional Kalimantan Selatan yang sudah jarang dijual di pasaran. Pada tahap I diberikan angket kepada peserta terkait materi yang disampaikan. Dari hasil angket diperoleh rerata pemahaman peserta terhadap materi yang diberikan sebesar 93,61\% sehingga kegiatan tahap I dinilai sudah berhasil.

Sedangkan kegiatan tahap II bertujuan agar guru dapat menyusun soal cerita berbasis kearifan local untuk meningkatkan kemampuan berpikir kreatif. Hasil 
lembar kerja kelompok yang dikerjakan oleh tim dibahas oleh narasumber bersama dengan peserta lain, sehingga peserta akan mendapatkan masukkan hasil pekerjaan yang telah dilaksanakan. Gambaran kegiatan tahap II disajikan pada Gambar 5 .

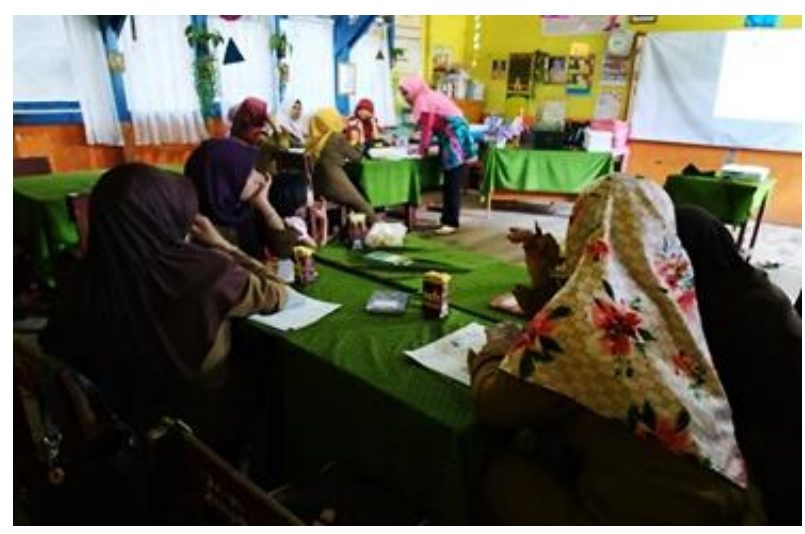

Gambar 5. Peserta mengerjakan berdiskusi dengan narasumber terkait tugas di lembar kerja kelompok

Pada Gambar 6 berikut disajikan salah satu hasil lembar kerja kelompok pada tahap II.

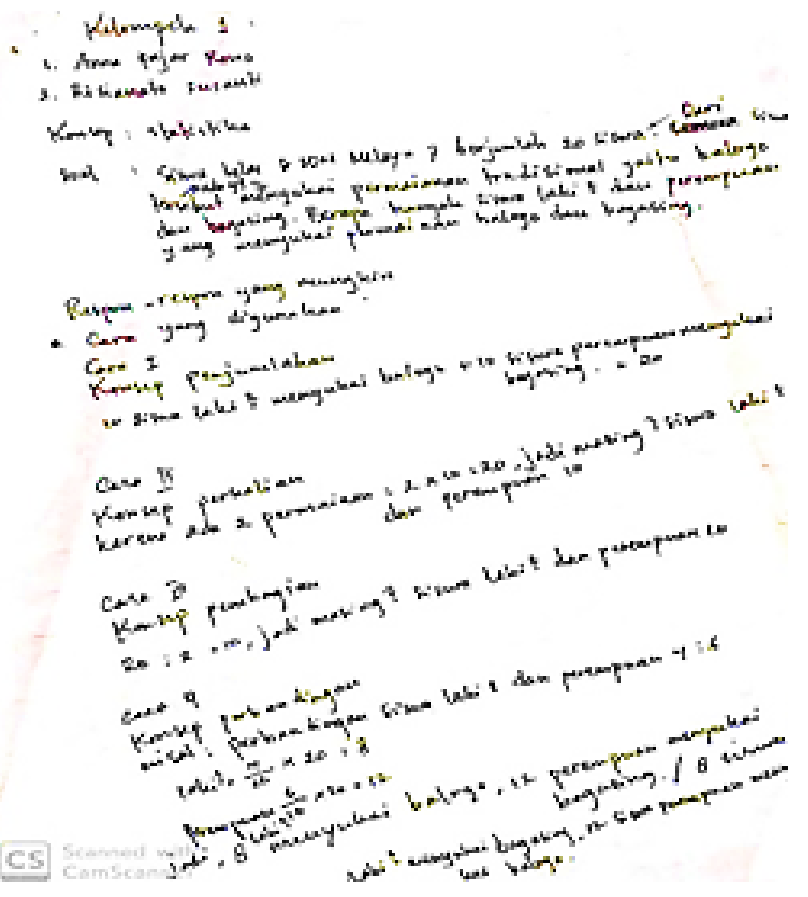

Gambar 6. Hasil kerja kelompok pada kegiatan tahap II

Pada Gambar 5 di atas terlihat soal yang dibuat merupakan soal dalam bentuk open ended dengan banyak cara untuk menyelesaikannya sehingga siswa dapat menyelesaikan dengan beragam strategi. Hal ini sejalan dengan penelitian Mustikasari et al. (2014) soalsoal open ended memberikan peluang kepada siswa untuk memberikan banyak pemecaham masalah dengan banyak strategi pemecahan masalah, sehingga dengan beragamnya jawaban yang diberikan siswa tersebut guru dapat mendeteksi kemampuan berpikir siswa. Kemampuan berpikir kreatif memungkinkan jika diberikan soal yang berbentuk open ended. Hasil angket pada tahap II diperoleh bahwa rerata pemahaman pesertaterhadap materi yang diberikan sebesar 91,94\% sehingga kegiatan tahap II dinilai sudah berhasil.

\section{KESIMPULAN}

Kegiatan pengabdian ini berjalan dengan lancar dan setiap tahapan berhasil dilaksanakan dengan tingkat pemahaman peserta yang mencapai $93,61 \%$ pada tahap I dan $91,94 \%$ pada tahap II. Selain itu dilihat dari hasil kerja kelompok dapat disimpulkan bahwa peserta dapat memahami dengan baik penjelasan yang diberikan oleh narasumber. Sehingga diharapkan hasil kegiatan ini dapat digunakan oleh guru untuk membuat soal cerita bagi siswa pada saat proses pembelajaran di kelas. Selanjutnya perlu dilakukan kegiatan lanjutan berupa penyusunan modul berbasis kearifan lokal untuk meningkatkan kemampuan berpikir kreatif siswa.

\section{UCAPAN TERIMA KASIH}

Terima kasih kami ucapkan kepada semua pihak yang mendukung kegiatan pengabdian ini, terutama kementerian ristekdikti yang telah memberikan dana untuk berlangsungnya kegiatan.

\section{REFERENSI}

Agustina, W., Noor, F. 2016. Hubungan Hasil Belajar dan Tingkat Berpikir Kreatif Siswa dalam Pembelajaran Matematika. Math Didactic: 
Jurnal Pendidikan Matematika. 2(3):191-200.

https://doi.org/10.33654/math.v2i3.49

Budiarti, I., Agustina, W. 2017. Pengembangan perangkat pembelajaran pendidikan matematika realistik (PMR) berbasis ethnomathematics sebagai upaya mengembangkan kreativitas siswa. Math Didactic: Jurnal Pendidikan Matematika. 3(3):178187. https://doi.org/10.33654/math.v3i3.70

Ekowati, D.W., Kusumaningtyas, D.I., Sulistyani, N. 2017. Ethnomathematica Dalam Pembelajaran Matematika (Pembelajaran Bilangan Dengan Media Batik Madura, Tari Khas Trenggal Dan Tari Khas Madura). JP2SD (Jurnal Pemikiran dan Pengembangan Sekolah Dasar). 5(2):716-721. https://doi.org/10.22219/jp2sd.v5i2.4820

Insani, M.D. 2016. Studi Pendahuluan Identifikasi Kesulitan Dalam Pembelajaran Pada Guru IPA SMP Se-Kota Malang. Jurnal Pendidikan Biologi. 7(2):81-93. http://dx.doi.org/10.17977/jpb.v7i2.723

Manizar, E. 2015. Peran Guru Sebagai Motivator Dalam Belajar. Tadrib: Jurnal Pendidikan Agama Islam. 1(2):204-222.

McComas, W.F. 2014. Trends in International Mathematics and Science Study (TIMSS). In: McComas W.F. (eds) The Language of Science Education. Rotterdam: SensePublishers. https://doi.org/10.1007/978-94-6209-4970_97

Mulyati, T. 2011. Kemampuan Pemecahan Masalah Matematis Siswa Sekolah Dasar. 3(2):1-15. https://doi.org/10.17509/eh.v3i2.2807

Mustikasari, Zulkardi, Aisyah, N. 2010. Pengembangan Soal-Soal Open-Ended Pokok Bahasan Bilangan Pecahan Di Sekolah Menengah Pertama. Jurnal Pendidikan Matematika. 4(2):4560. https:/ /doi.org/10.22342/jpm.4.2.820.

Noor, F., Agustina, W. 2016. Hasil Belajar Matematika dan Tingkat Berpikir Kreatif Siswa SMP dalam Pembelajaran Berbasis Masalah yang Terintegrasi Pendekatan Saintifik. Math Didactic: Jurnal Pendidikan Matematika. 2(3):171180. https:/ / doi.org/10.33654/math.v2i3.46

Pemerintah Provinsi Kalimantan Selatan. 2016. Rencana Strategis Dinas Pendapatan Daerah Provinsi Kalimantan Selatan Tahun 2016-2021.
Banjarmasin: Pemerintah Provinsi Kalimantan Selatan.

Pemerintah Republik Indonesia. 2010. Peraturan Pemerintah Nomor 17 Tahun 2010 Tentang Pengelolaan dan Penyelenggaraan Pendidikan.

Polya, G. 1973. How to Solve It: A New Aspect Mathematical Method. New Jersey: Princeton University Press.

Rafiah, H., Ekawati, A. 2017. Misconceptions of the Students with High Mathematical Creative Thinking Level in Solving the Geometric Shapes Problems. In Pasani, C.F., Winarti, A., Wati, M., Mu'in, F. (Eds.) Proceedings of the 5th SEA-DR (South East Asia Development Research) International Conference 2017 (SEADRIC 2017). 100:155-159.

https://dx.doi.org/10.2991/seadric17.2017.33

Rahmawati, A. 2019. Analisis Kesulitan Siswa Dalam Menyelesaikan Soal Cerita Matematika Berbasis Pembelajaran Pemecahan Masalah Kelas V SD Negeri Gebangsari 03. Jurnal Pengembangan Pembelajaran Matematika (JPPM). 1(2):46-51.

Rasyid, M.R. 2008. Optimalisasi Peran Guru Dalam Proses Transformasi Pengetahuan Dengan Menggunakan Media Pembelajaran. Lentera Pendidikan: Jurnal Ilmu Tarbiyah dan Keguruan. 11(1):55-68. https://doi.org/10.24252/lp.2008v11n1a5

Sa'djiah, C., Rafiah, H., Gipayana, M., Qohar, A., Anwar, L. 2016. Asesmen Pemecahan Masalah OpenEnded Untuk Mengukur Profil Berpikir Kreatif Matematis Siswa Berdasar Gender. Sekolah Dasar: Kajian Teori dan Praktik Pendidikan. 25(2):147-159. http://dx.doi.org/10.17977/um009v25i22016 p147

Siswono, T.Y.E. 2005. Upaya meningkatkan kemampuan berpikir kreatif siswa melalui pengajuan masalah. Jurnal Pendidikan Matematika dan Sains. 10(1):1-9. 